\title{
Magnetic detection of sentinel lymph node in papillary thyroid carcinoma: The MAGIC-PAT study results
}

\author{
Juan Antonio Baena Fustegueras a, *, Fernando Herrerías González a , \\ Sònia Gatius Calderó ${ }^{\mathrm{b}}$, Ma Cruz de la Fuente Juárez ${ }^{\mathrm{a}}$, Susana Ros López ${ }^{\mathrm{c}}$, \\ Ferran Rius Riu ${ }^{\mathrm{d}}$, Núria Mestres Petit ${ }^{\mathrm{a}}$, Pablo Muriel Álvarez ${ }^{\mathrm{a}}$, Albert Lecube Torelló ${ }^{\mathrm{d}}$, \\ Xavier Matias-Guiu ${ }^{b}$, Jorge Juan Olsina Kissler ${ }^{a}$ \\ a Surgery Unit, Arnau de Vilanova University Hospital, 25198, Lleida, Spain \\ b Pathology Unit, Arnau de Vilanova University Hospital, 25198, Lleida, Spain \\ c Surgery Unit, Lozano Blesa University Clinical Hospital, 50009, Zaragoza, Spain \\ d Endocrinology Unit, Arnau de Vilanova University Hospital, 25198, Lleida, Spain
}

\section{A R T I C L E I N F O}

Article history:

Received 27 September 2018

Received in revised form

5 March 2019

Accepted 11 March 2019

Available online $\mathrm{xxx}$

Keywords:

Magnetic tracer

Sentinel lymph node biopsy

Superparamagnetic iron oxide (SPIO)

Thyroid carcinoma

\begin{abstract}
A B S T R A C T
Introduction: Despite the controversy concerning sentinel lymph node biopsy (SLNB) in papillary thyroid carcinoma (PTC), successful detection rates can be achieved by radioguidance and vital dyeing. However, the drawbacks in both techniques are notable. Magnetic-guided SLNB (mSLNB) using superparamagnetic iron oxide (SPIO) nanoparticles is appealing as an alternative procedure.

Materials and Methods: mSLNB using the Sentimag-Sienna System ${ }^{\circledR}$, total thyroidectomy and central compartment dissection (CCD) were performed on all PTC patients. Lymph node involvement was assessed by postoperative pathological examination.

Results: From 2014 to 2016, 33 consecutive patients with PTC were enrolled in the study. A total of 20 patients met the eligibility. mSLNB succeeded in 16 patients, with a detection rate of $80 \%$. A median of two SLN per patient were detected. A median of 10.5 non-sentinel lymph nodes (NSLN) from CCD were examined. Among the patients, $56.25 \%(9 / 16)$ had no metastatic nodes, while $12.5 \%(2 / 16)$ had exclusively SLN involvement. No false negative cases were found. The agreement between SLN and NSLN status was $87.5 \%$. The prediction of NSLN involvement by SLN status showed $100 \%$ sensitivity, $81.8 \%$ specificity, $71.4 \%$ PPV and 100\% NPV. Subsequently, mSLNB and the final pathological analysis would discriminate $43.75 \%$ (7/16) of patients who would certainly benefit from CCD whilst $56.25 \%$ of the total would confirm an unnecessary lymphadenectomy and avoid morbidity.

Conclusion: mSLNB showed satisfactory performance in PTC with clinical-negative nodes. We have shown mSLNB to be a good predictor of central compartment status that can improve the staging and management of PTC patients.
\end{abstract}

(c) 2019 Elsevier Ltd, BASO The Association for Cancer Surgery, and the European Society of Surgical Oncology. All rights reserved.
Abbreviations: AJCC, American Joint Committee on Cancer; ATA, American Thyroid Association; CCD, central compartment dissection; DTC, differentiated thyroid cancer; ETE, extrathyroidal extension; FNR, false negative ratio; LN, lymph nodes; MRI, magnetic resonance imaging; mSLNB, magnetic sentinel lymph node biopsy; NPV, negative predictive value; NSLN, non-sentinel lymph node; OSNA one-step nucleic acid amplification; PPV, positive predictive value; PTC, papillary thyroid cancer; SC, sentinel compartment; SLN, sentinel lymph nodes; RAI, radioactive iodine; rSLNB, radio-guided; SLN, sentinel lymph node; SLNB, sentinel lymph node biopsy; SPIO, superparamagnetic iron oxide.

* Corresponding author. Endocrine Surgery Unit, Arnau de Vilanova University Hospital, Av. Alcalde Rovira Roure, 80, 25198, Lleida, Spain.

E-mail address: jabaena@vhebron.net (J.A. Baena Fustegueras).

\section{Introduction}

Differentiated thyroid cancer (DTC) is the most common endocrine malignancy. Papillary carcinoma represents 60-70\% among all thyroid carcinomas. Surgical treatment of papillary thyroid cancer (PTC) is carried out by total thyroidectomy and neck dissection in patients with clinical involvement of nodes or cT3/cT4 $[1,2]$. Nevertheless, "prophylactic" central neck dissection in patients with clinically negative lymph nodes is still controversial [3]. In comparison with simple thyroidectomy, CCD causes higher postsurgical adverse effects such as hypoparathyroidism or 
recurrent laryngeal nerve lesions, particularly when bilateral central compartment lymphadenectomy is performed [3-5].

The prevalence of nodal involvement associated with PTC is significant, especially in high-risk patients (up to 75\%) [6,7]. Moreover, nodal involvement affects the survival of patients older than 45 or with other risk factors [8]. There is a clear association between nodal involvement and loco-regional recurrence, as such surgery is the optimal treatment [2]. However, morbidity after surgery to review recurrence is also remarkable. Apart from other consequences, permanent recurrent nerve paralysis and hypoparathyroidism are not uncommon, there might be a need for a voluntary parathyroid gland and recurrent nerve resection due to involvement, as well as compressive haematoma or temporary tracheostomy while even cases of fatalities have been described [9-13].

The sentinel lymph node (SLN) is defined as the first lymph node receiving lymphatic drainage from a primary tumour, being the first node to be affected by metastasis. Hence, low or no likelihood of distant lymphatic spread is assumed for histologically negative SLN. The concept of SLN is currently established in melanoma, vulvar and breast cancer patients, and it is being assessed in other types of solid tumours including differentiated thyroid carcinoma [14-16]. In thyroid cancer, SLN biopsy (SLNB) has been addressed using blue dyes [17,18], radioisotopes [4,19-22] or the combination of both [23]. The pooled detection rate of vital dyes is $15 \%$ lower than the rate for radioguided SLNB [24]. The drawbacks of using radiotracers with lymphoscintigraphy include radiation exposure and the need for nuclear medicine facilities, while allergic reactions have been associated with blue dyeing [25]. In PTC, the SLNB contributes to an accurate perioperative staging of the disease $[6,9,10]$ and could help in selecting patients who would certainly benefit from CCD while avoiding unnecessary surgery and its associated morbidity $[2,6,26]$. However, the current clinical guidelines for PTC management do not consider the SLNB procedure due to the high false negative ratio (FNR) in intraoperative SLN analysis [27].

The Sentimag-Sienna System ${ }^{\circledR}$ is a new technology for SLNB based on a magnetic tracer. Superparamagnetic iron oxide (SPIO) has been used for over 20 years as an intravenous contrast agent for magnetic resonance imaging (MRI) [28]. Due to the superparamagnetic conduct, the response of SPIO to an external magnetic field and its magnetic properties disappears if the magnetic field is discontinued. The Sienna $+{ }^{\circledR}$ SPIO tracer is covered by carboxidextran, which prevents agglomeration while preserving biocompatibility. The particle size, with a median diameter of $60 \mathrm{~nm}$ including the organic cover, allows for the selective filtering of Sienna $+{ }^{\circledR}$ by lymph nodes (LN), lymphatic drainage and final accumulation in the nodes. Hence, the SPIO in nodes can be detected using the Sentimag ${ }^{\mathbb{R}}$ handheld magnetometer. The feasibility of SPIO and the Sentimag-Sienna System ${ }^{\circledR}$ has been already proven for SLNB in breast cancer with detection rates equal to the reference methodology such as radiotracer or radiotracer combined with blue dye [29-34].

The aim of this study was to evaluate the Sentimag-Sienna System ${ }^{\circledR}$ for SLNB in PTC patients with PTC and clinically negative nodes. The performance of magnetic-guided SLNB to predict node involvement in the central compartment was also investigated.

\section{MATERIALS and METHODS}

Study design

This is prospective single-institution study. Consecutive patients with thyroid cancer from 2013 to 2016 were considered for the study. The inclusion criteria were pathological confirmation of papillary thyroid carcinoma, clinical-negative lymph nodes in the central compartment and non-lateral compartment involvement, as well as no previous surgical treatment in the cervical area. Patients were excluded if any contraindication to magnetic tracer such as intolerance to iron or dextran compounds, high iron concentration disorders or metallic implants existed. The study was approved by the Ethics Committee of the Arnau de Vilanova University Hospital in Lleida, Spain (reference MAGIC-PAT). Only eligible patients who provided the signed informed consent were enrolled in the study.

\section{SLNB procedure with magnetic tracer}

All patients were subjected to a total thyroidectomy with central compartment dissection through a standard Kocher incision. After the thyroid gland dissection, the SPIO magnetic tracer Sienna $+{ }^{\circledR}$ (Endomagnetics Ltd, UK) was peritumoral injected, following the manufacturer's instructions. A 5-min massage was performed to trigger the tracer's migration into the LN. The handheld Sentimag ${ }^{\circledR}$ magnetometer (Endomagnetics Ltd, UK) was used to detect the magnetic field 20 min post-injection, and the magnetic count was checked at the injection point and central compartment region. Subsequently, a total thyroidectomy was performed and the magnetic count in the central compartment was tested. The dissection of SLN was stopped if the node count was less than $5 \%$ of the maximum count. Finally, central compartment dissection was performed. No metal surgical instruments or armoured endotracheal tubes were used in the surgical procedure to prevent interference. All mSLNB procedures were performed by the same surgeon (JAB). The sentinel compartments were referred to postoperative pathological examination.

\section{Pathological assessment}

As the limited operative area in the central compartment made occasionally difficult to dissect individual SLN in vivo, the presence and number of LNs in the tissue excised, we called sentinel compartment (SC), was assessed in the post-operative pathological study. The status of SLN and non-sentinel lymph nodes (NSLN) from the central compartment dissection was assessed following current pathology laboratory practice (AJCC 7th Ed.) [6,35].

\section{Statistical analyses}

The descriptive analysis of the variables was carried out by dispersion and central tendency parameters. Quantitative variables were described using means and standard deviations. Per node analysis was conducted for the global pathological LN results. Per patient data analysis was performed for mSLNB procedure and prediction of CC status. With regards to the central compartment status prediction, true SLN was assumed if either positive SLN or the negative status of both SLN and NSLN was observed. Negative SLN but positive NSLN was considered a false negative case. The FNR of SLNB as a predictor of the central compartment status was defined as the proportion of false negative cases over histologically positive NSLN cases.

\section{Results}

\section{SLNB procedure with magnetic tracer}

A total of 31 patients with a diagnosis of PTC were enrolled in the study. Eleven cases were excluded due to not complying with the eligibility criteria. Among them, 7 cases were excluded due to 
perioperative N1 stage (lateral compartment dissection proceed), 2 misplaced tumour nodes, 1 incompatibility with the surgical procedure and magnetic tracer (metal instruments), and 1 case due to missing data (Fig. 1).

Therefore, 20 patients met the eligibility criteria to evaluate the performance of SLNB. The clinical-pathological characteristics of these patients are depicted in Table 1 . Out of the total, $75 \%$ of patients were women. The average age was 54.8 years. A single tumour node was found in $75 \%$ cases. The patients had clinical T1 (50\%) and T2 (50\%) tumours. Final pathological examination evidenced $60 \%(12 / 20)$ cases with pT3 tumours. The pathological examination of LN after CCD evidenced 45.0\% (9/20) patients with nodal involvement ( $\mathrm{pN} 1)$.

The sentinel compartment was excised in 17 cases (Table 2). In $82.4 \%(14 / 17)$ of patients, a single area was detected. In 3 (17.6\%) cases, two different areas were excised. Among the 20 patients, 16 had successful SLNB while 4 cases failed to detect SLN. Three failures occurred due to the non-migration of magnetic tracer and 1 case failed since non-lymphatic tissue was detected in the pathological assessment. The SLNB detection rate using the magnetic tracer was $80 \%(16 / 20)$.

\section{Lymph node involvement}

A median of 12 (3-23) LN per patient were assessed (Table 3). The ratio of metastatic nodes was $14.0 \%$ (32/229), with a median of $0(0-10)$ positive LN per patient. A total of 42 SLN were identified with a median of 2 SLN per patient. Two SLN were detected in 50\% $(8 / 16)$ cases. The ratio of metastatic SLN was $31.0 \%$ (13/42), with a range of zero to four positive SLN per patient. In $12.5 \%(2 / 16)$ of cases only the SLN had metastases. The amount of non-sentinel lymph nodes (NSLN) in CCD was 187 , with a median of $10(2-18)$ NSLN per patient. The ratio of metastases in NSLN was $10.2 \%$ (19/ 187).
Table 1

Clinic and pathological characteristics of PTC patients.

\begin{tabular}{ll}
\hline Patients $(\mathrm{n}=20)$ & $\mathrm{N}(\%)$ \\
\hline Age $^{\mathrm{a}}$ & $56(22-78)$ \\
\hline Gender & $5(25.0 \%)$ \\
Male & $15(75.0 \%)$ \\
Female & \\
\hline Clinical diagnose & $7(35.0 \%)$ \\
Palpation & $11(55.0 \%)$ \\
Ultrasound & $2(10.0 \%)$ \\
Others & \\
\hline Tumour location & $8(40 \%)$ \\
Right lobe & $9(45 \%)$ \\
Left lobe & $3(5 \%)$ \\
Isthmus & \\
\hline Multifocality & $15(75.0 \%)$ \\
No & $5(25.0 \%)$ \\
Yes & $16.5(8.0-53.0)$ \\
\hline Tumour size (max in image) ${ }^{\mathrm{a}}$ & \\
\hline Clinical T stage & $10(50 \%)$ \\
T1 & $10(50 \%)$ \\
T2 & \\
\hline pT stage & $3(15.0 \%)$ \\
T2 & $5(25.0 \%)$ \\
T3 & $12(60.0 \%)$ \\
\hline pN stage & \\
N0 $11(55.0 \%)$ \\
\hline N1 & $9(45.0 \%)$ \\
\hline & \\
\hline & \\
\hline
\end{tabular}

${ }^{\text {a }}$ Data as median and range.

\section{SLNB as predictor of central compartment status}

Among the patients, 56.25\% (9/16) had no nodal involvement in the central compartment (pN0). Out of the total, $43.75 \%(7 / 16)$ of

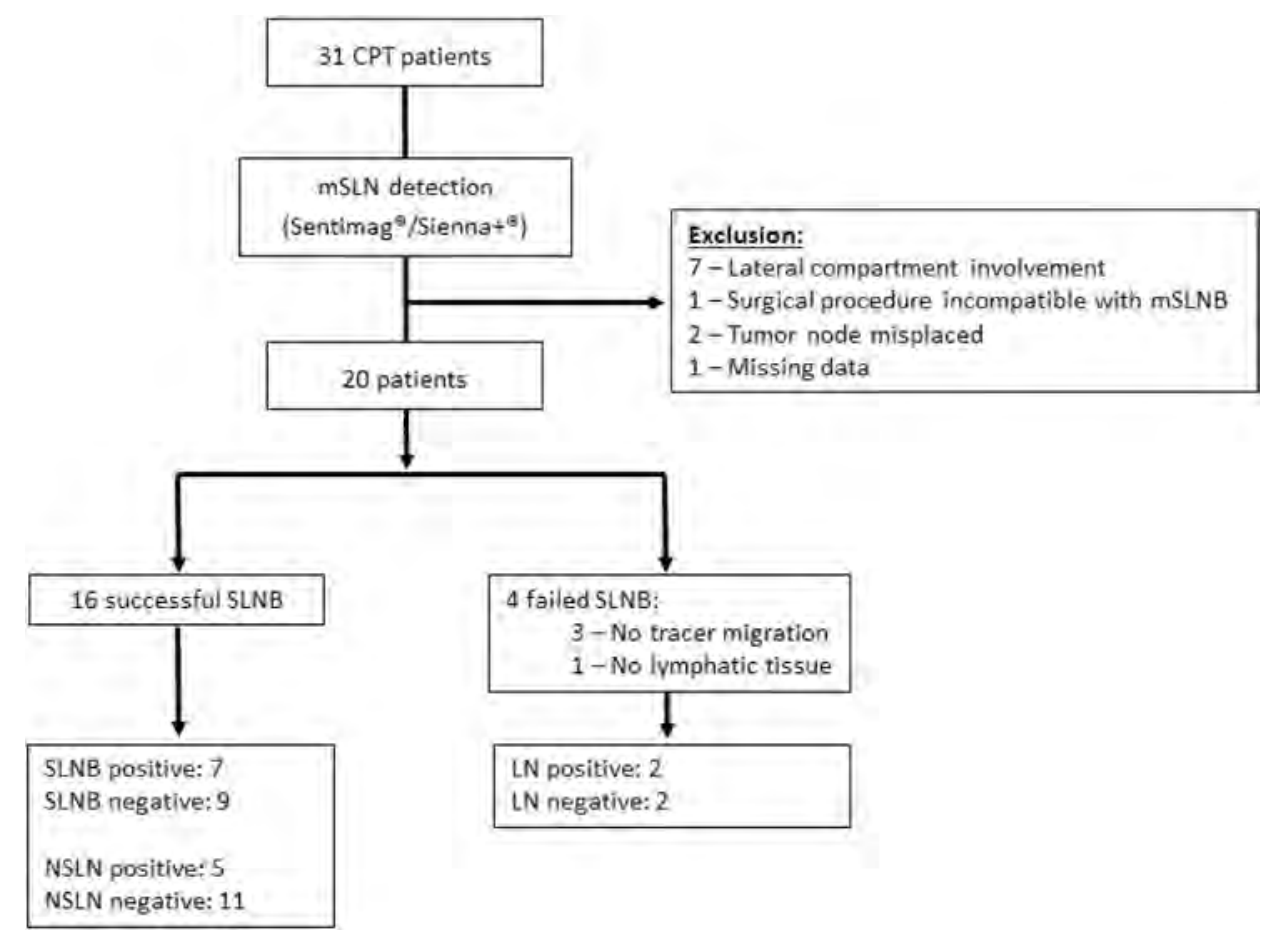

Fig. 1. CONSORT flow diagram of study patients.

LN, lymph node; NSLN, non-sentinel lymph node; SLN, sentinel lymph node; mSLNB, magnetic sentinel lymph node biopsy. 
Table 2

Sentinel lymph node procedure using SPIO with Sentimag-Sienna System $^{\circledR}$.

\begin{tabular}{ll}
\hline & $\mathrm{N}(\%)$ \\
\hline $\begin{array}{l}\text { Magnetic tracer migration } \\
\text { Yes }\end{array}$ & $17(85.0 \%)$ \\
No & $3(15.0 \%)$ \\
\hline Magnetic tracer count $^{\mathrm{a}}$ & \\
Compartment 1 & $800(150-5.600)$ \\
Compartment 2 & $1.300(500-5.700)$ \\
\hline Sentinel Compartment (n=17) & \\
$\mathrm{N}^{\mathrm{o}}$ areas excised & \\
1 & $17(85.0 \%)$ \\
2 & $3(15.0 \%)$ \\
Lymphatic Node & $16(94.1 \%)$ \\
Yes & $1(5.9 \%)$ \\
No & \\
$\mathrm{N}^{\circ}$ lymph nodes & $1(5.9 \%)$ \\
0 & $4(23.5 \%)$ \\
1 & $8(47.1 \%)$ \\
2 & $1(5.9 \%)$ \\
3 & $2(11.8 \%)$ \\
5 & $1(5.9 \%)$ \\
9 & \\
\hline Lymphatic drainage & $13(65.0 \%)$ \\
ipsilateral & $0(0.0 \%)$ \\
contralateral & $2(12.5 \%)$ \\
central & $2(12.5 \%)$ \\
\hline
\end{tabular}

${ }^{a}$ Data as median and range.

Table 3

Lymph node assessment in successful sentinel lymph node biopsy.

\begin{tabular}{lll}
\hline & Mean $(\mathrm{SD})$ & Median (min, max) \\
\hline Lymph nodes & & \\
$\mathrm{N}^{\circ}$ total LN $(\mathrm{n}=229)$ & $11.5(6.0)$ & $12(3-23)$ \\
$\mathrm{N}^{\circ}$ LN metastases $(\mathrm{n}=32)$ & $1.6(2.5)$ & $0(0-9)$ \\
& & \\
Sentinel Compartment & & \\
$\mathrm{N}^{\circ}$ SLN detected $(\mathrm{n}=42)$ & $2.6(2.1)$ & $2(1-9)$ \\
$\mathrm{N}^{\circ}$ SLN metastases $(\mathrm{n}=13)$ & $0.8(1.2)$ & $0(0-4)$ \\
& & \\
Central Compartment Dissection & & $10(2-18)$ \\
$\mathrm{N}^{\circ}$ NSLN detected $(\mathrm{n}=187)$ & $9.4(5.4)$ & $0(0-7)$ \\
$\mathrm{N}^{\circ}$ NSLN metastases $(\mathrm{n}=19)$ & $1.0(1.9)$ & \\
\hline
\end{tabular}

LN, lymph nodes; NSLN, non-sentinel lymph nodes.

patients had positive SLN (Table 4). Among them, 28.6\% (2/7) had negative NSLN and $71.4 \%(5 / 7)$ had positive NSLN. No significant differences were observed ( $p$-value $=0.5$, McNemar test). No false negative cases were found; all patients with positive NSLN had positive SLN. The performance to predict NSLN involvement by SLNB status showed $100 \%$ sensitivity, $81.8 \%$ specificity, $71.4 \%$ PPV and $100 \%$ NPV, with an accuracy of $87.5 \%$.

\section{Discussion}

Different strengths of recommendations are reported in the current guidelines for the management of thyroid cancer [36-39]. Currently, the American Thyroid Association (ATA) recommends avoiding $\mathrm{CCD}$ for small (T1 or T2), non-invasive, clinically negative nodes PTC ( $\mathrm{cNO}$ ) and for most follicular cancers [2]. On the other hand, prophylactic CCD should be considered in cNO patients who have advanced primary tumours (T3 or T4), clinical involvement of lateral neck nodes (cN1b), or when the information will be used to plan further steps in therapy. Nonetheless, the prophylactic
Table 4

Predictive performance of the central compartment status by sentinel lymph node biopsy.

\begin{tabular}{|c|c|c|c|c|}
\hline & & \multicolumn{2}{|l|}{ NSLN } & \\
\hline & & + & - & \\
\hline \multirow[t]{3}{*}{ SLN } & + & 5 (31.25\%) & $2(12.50 \%)$ & 7 \\
\hline & - & $0(00.00 \%)$ & $9(56.25 \%)$ & 9 \\
\hline & & 5 & 11 & 16 \\
\hline \multicolumn{2}{|c|}{ Accuracy } & & & $87.5 \%$ \\
\hline \multicolumn{2}{|c|}{ Se } & & & $100.0 \%$ \\
\hline \multicolumn{2}{|l|}{ Sp } & & & $81.8 \%$ \\
\hline \multicolumn{2}{|c|}{ PPV } & & & $71.4 \%$ \\
\hline \multicolumn{2}{|c|}{ NPV } & & & $100.0 \%$ \\
\hline
\end{tabular}

SLN, sentinel lymph node; NSLN, non-sentinel lymph node; Se, sensitivity; Sp, specificity; PPV, positive predictive value; NPV, negative predictive value.

performance of central lymph node dissection is currently under debate [3]. Defenders state that the procedure results in minimal morbidity, reduces the postoperative thyroglobulin levels and the risk of recurrence. Opponents to routine dissection underscore the higher risk of postsurgical hypoparathyroidism, the increased risk of recurrent laryngeal nerve lesions and the lack of evidence concerning improved clinical outcomes. Therefore, we aim to investigate the feasibility of SLNB using SPIO to discriminate patients who would certainly benefit from central compartment dissection, the clinical staging notwithstanding. At present this is the first study reporting SLNB guided by a magnetic tracer in PTC.

The meta-analysis of Balasubramanian and Harrison showed pooled detection rates of $84 \%$ and $98 \%$ for vital dyes and the radioisotope technique, respectively [20]. The low sensitivity, close to $65 \%$, and the FNR over $30 \%$ of blue dyeing make the technique inadequate for routine procedures [18]. Moreover, the adverse reactions and unavoidable staining of parathyroid glands increase their drawbacks [15]. Radio-guided SLN (rSLNB) achieves better detection rates in comparison with vital dyes, avoids lymphatic disruption during surgery and false negative from parathyroid glands, and allow SLN outside the central compartment to be identified $[24,40]$. Recently, other methodologies such as carbon nanoparticle suspension are being investigated as a technique for SLNB and parathyroid gland recognition [41,42]. We achieved satisfactory mSLNB performance with an $80 \%$ detection rate. In addition, we observed satisfactory accuracy of mSLNB for NSLN status based on definitive pathological assessment of LN, with $100 \%$ sensitivity and $100 \%$ NPV, which supports the methodology as a surgical procedure to stage PTC more effectively with clinicalnegative nodes in the central compartment. Interestingly, in our case series there were no false negative cases of SLN according to NSLN status whereas other studies that have attempted postoperative pathological analysis have reported higher false negative SLN [27]. However, the reduced sample size limits the statistical significance of our results and further studies with extended series of patients are needed to enhance and confirm the results.

SPIO offers an alternative procedure for SLNB in breast cancer with notable detection rates, equal to the reference by rSLNB [29-34]. Directly managed by surgeons, the SPIO technique using Sentimag-Sienna System ${ }^{\circledR}$ helps to avoid radiological exposure in addition to offering an operative solution to institutions without nuclear medicine facilities. Managing mSLNB in thyroid cancer is likely to demand further surgical expertise due to the limited operative area in the central compartment making it difficult to dissect individual SLN. Therefore, the sentinel compartment concept may be favoured over the SLN for MSLNB procedure in PTC. Nonetheless, we mostly retrieved $1-2$ SLN per patient though one 
patient had up to 9 SLN, who eventually evidenced pathologically negative nodes. Additionally, the tracer dose and injection method may need to be adjusted for thyroid carcinoma due to the tumour size and surgical area in comparison with what is established in breast cancer.

Current ATA guidelines do not recommend CCD in PTC patients with T1-T2 and no clinical evidence of LN metastasis. Rubello et al. argued that the rSLNB procedure may help to improve patient staging due to the high ratio of metastases in deferred histological examination while negative SLN could lead to radio-metabolic therapy [40]. Extrathyroidal extension (ETE) as well as nodal involvement are considered prognostic risk factors in PTC [43-45]. Additionally, a 10-year follow-up of 253 patients showed a higher risk of recurrence in accordance with $\mathrm{T}$ and $\mathrm{N}$ stages [46]. In fact, $50 \%(4 / 8)$ of pathological-confirmed T1/T2 patients included in the study showed central neck node involvement. Therefore, mSLNB improved nodal staging that could have guided surgeons to proceed with selective prophylactic CCD. On the other hand, the final pathological examination showed $60 \%(12 / 20)$ of cases with a T3 tumour, all cases with minimal ETE. Among them, 7 (58.3\%) cases were pNO. ATA guidelines recommend therapeutic CCD in T3 tumours. Our results, suggest that mSLNB can improve nodal staging of patients with minimal ETE, helping surgeons to decide to discontinue CCD. These results are in line with guidelines, with nodal invasion extension a better clinical factor to proceed with CCD rather than tumour size. However, we must be aware that skip metastases in patients with negative central neck reaches up to $20 \%$ $[36,47]$. Consequently, the controversy surrounding the lymph node dissection with regards to SLNB is still present. Further prospective studies should be addressed in order to evaluate the clinical value and prognosis of patients managed according to mSLNB status.

In our series, CCD evidenced up to $45 \%$ (9/20) patients with nodal involvement in the central compartment. Of these patients, $77.8 \%$ (7/9) had mSLNB, all cases with positive SLN (Table 5). Two cases had only SLN affected. As SLNB dissection removed the whole tumour load in the central compartment, these patients would not have benefited from further CCD extension but would have experienced its drawbacks. Although isolated tumour cells by histological assessment denotes positive SLN, it is unlikely to find further NSLN involvement. Using a more accurate method for $\mathrm{LN}$ assessment, such as molecular assays, would contribute to improving the prediction of $\mathrm{LN}$ as has been proven in breast cancer patients [48]

Besides, the feasibility of SLNB in PTC is still under discussion due to the high rate of intraoperative false negatives [27]. Despite the high detection rate of rSLNB, an overall intraoperative FNR of $25.4 \%$ has been reported in the meta-analysis of studies that conducted SLN and lymphadenectomy in the same compartment [27]. Portinari and Carcofor suggest that considering the high FNR, rSLNB status alone cannot justify the neck dissection procedure, rather it can improve locoregional nodal staging and selection for postoperative radioiodine ablation therapy $[27,36]$. However, authors argue that based on lymphatic drainage rSLNB can lead to extending dissection in a specific neck compartment (i.e., central or lateral). Cunningham et al. reached a satisfactory $90 \%$ SLN detection rate using blue dye but with a high FNR (34\%) of intraoperative analysis of SLN status with the frozen section, with $60 \%$ negative NSLN after CCD pathological examination [21]. Pelizzo et al. had a 99\% rSLNB detection rate and conducted lymphadenectomy only in the same compartment of the SLN according to the frozen section [16]. However, they found a disease persistence of $5.1 \%$, likely due to the selective compartment dissection or high FNR in the frozen section analysis. Unfortunately, no data was available regarding the status of NSLN in patients with negative SLN, and subsequently, the false negative SLN and FNR in the final pathological analysis could not be evaluated. Interestingly, some studies indicate the molecular assay OSNA (one-step nucleic acid amplification) as a useful and accurate method to detect LN metastasis in PTC [49,50]. Therefore, intraoperative SLNB using OSNA could contribute to decreasing the FNR formed by missed occult metastases in the intraoperative frozen sections. Further studies should be addressed to investigate the feasibility of mSLNB using SPIO in combination with the OSNA assessment of SLN.

Neck dissection is known to increase morbidity, hospitalization and costs [7]. However, rSLNB demands special facilities and also entails adverse radiological effects on physicians and patients. Balasubramanian et al. stated that even though morbidity attributable to CCD may be avoided, rSLNB implementation for selective prophylactic CCD even in ideal conditions (100\% detection rate, $100 \%$ sensitivity and $0 \%$ FNR) has low cost benefits [51]. In contrast, our results suggest that mSLNB could overcome such limitations

Table 5

Node involvement and characteristics of PTC patients subjected to mSLNB.

\begin{tabular}{|c|c|c|c|c|c|c|c|c|c|c|c|c|c|c|c|c|c|}
\hline ID & Gender & Age & $\begin{array}{l}\text { Clinical } \\
\text { diagnosis }\end{array}$ & $\begin{array}{l}\text { cT } \\
\text { stage }\end{array}$ & $\begin{array}{l}\text { Tumour } \\
\text { localization }\end{array}$ & Multifocality & $\begin{array}{l}\text { Tumour size } \\
(\mathrm{mm})\end{array}$ & $\begin{array}{l}\text { Tracer } \\
\text { migration }\end{array}$ & $\begin{array}{l}\mathrm{LN} \\
\text { drainage }\end{array}$ & $\begin{array}{l}\mathrm{N}^{\circ} \\
\mathrm{SC}\end{array}$ & SC_LN & $\begin{array}{l}\mathrm{N}^{\circ} \\
\text { SLN }\end{array}$ & $\begin{array}{l}\text { positive } \\
\text { SLN }\end{array}$ & $\begin{array}{l}\mathrm{N}^{\circ} \\
\mathrm{NSLN}\end{array}$ & $\begin{array}{l}\text { positive } \\
\text { NSLN }\end{array}$ & $\begin{array}{l}\text { pT } \\
\text { stage }\end{array}$ & $\begin{array}{l}\mathrm{pN} \\
\text { stage }\end{array}$ \\
\hline 1 & $\mathrm{~m}$ & 53 & ultrasound & $\mathrm{T} 1$ & right & no & 15 & yes & ipsilateral & 1 & yes & 5 & 1 & 18 & 1 & $\mathrm{~T} 1$ & N1 \\
\hline 2 & $\mathrm{f}$ & 69 & ultrasound & $\mathrm{T} 2$ & left & no & 40 & yes & ipsilateral & 1 & yes & 1 & 1 & 14 & 1 & $\mathrm{~T} 2$ & N1 \\
\hline 3 & $\mathrm{f}$ & 54 & others & $\mathrm{T} 2$ & right & yes & 22 & yes & ipsilateral & 1 & yes & 1 & 1 & 11 & 5 & T3 & N1 \\
\hline 4 & $\mathrm{f}$ & 50 & others & $\mathrm{T} 1$ & isthmus & no & 15 & yes & central & 1 & yes & 2 & 0 & 16 & 0 & T3 & NO \\
\hline 6 & $\mathrm{f}$ & 36 & palpation & $\mathrm{T} 2$ & right & no & 21 & yes & ipsilateral & 1 & yes & 2 & 2 & 17 & 7 & $\mathrm{~T} 2$ & N1 \\
\hline 7 & $\mathrm{~m}$ & 67 & ultrasound & $\mathrm{T} 2$ & left & yes & 30 & yes & ipsilateral & 1 & yes & 2 & 0 & 12 & 0 & $\mathrm{~T} 2$ & NO \\
\hline 8 & $\mathrm{~m}$ & 69 & palpation & $\mathrm{T} 1$ & right & yes & 15 & yes & ipsilateral & 2 & yes & 2 & 0 & 10 & 0 & T3 & NO \\
\hline 9 & $\mathrm{f}$ & 55 & ultrasound & $\mathrm{T} 1$ & left & no & 18 & no & - & - & - & - & - & 5 & 0 & $\mathrm{~T} 1$ & NO \\
\hline 10 & & 77 & ultrasound & $\mathrm{T} 2$ & left & yes & 25 & yes & ipsilateral & 1 & yes & 1 & 0 & 2 & 0 & $\mathrm{~T} 2$ & NO \\
\hline 11 & & 60 & palpation & $\mathrm{T} 1$ & left & no & 10 & yes & ipsilateral & 1 & yes & 9 & 0 & 6 & 0 & T3 & NO \\
\hline 12 & & 22 & ultrasound & $\mathrm{T} 1$ & left & no & 18 & yes & ipsilateral & 1 & yes & 3 & 3 & 16 & 2 & T3 & N1 \\
\hline 13 & & 37 & palpation & $\mathrm{T} 1$ & right & no & 15 & no & - & 1 & yes & - & - & 11 & 1 & T3 & N1 \\
\hline 14 & & 55 & ultrasound & $\mathrm{T} 2$ & isthmus & yes & 8 & yes & central & 1 & no & - & - & 3 & 0 & $\mathrm{~T} 1$ & NO \\
\hline 15 & & 60 & ultrasound & $\mathrm{T} 1$ & right & no & 15 & yes & ipsilateral & 1 & yes & 2 & 0 & 2 & 0 & T3 & NO \\
\hline 17 & & 78 & palpation & $\mathrm{T} 2$ & left & no & 50 & no & - & - & - & - & - & 5 & 2 & T3 & N1 \\
\hline 18 & & 58 & ultrasound & $\mathrm{T} 1$ & left & no & 10 & yes & ipsilateral & 1 & yes & 2 & 0 & 10 & 0 & T3 & NO \\
\hline 19 & & 28 & palpation & $\mathrm{T} 2$ & left & no & 48 & yes & bilateral & 2 & yes & 5 & 4 & 3 & 0 & $\mathrm{~T} 2$ & N1 \\
\hline 20 & & 29 & palpation & $\mathrm{T} 2$ & right & no & 18 & yes & ipsilateral & 1 & yes & 1 & 1 & 6 & 0 & T3 & N1 \\
\hline 21 & & 66 & ultrasound & $\mathrm{T} 1$ & right & no & 10 & yes & ipsilateral & 1 & yes & 2 & 0 & 15 & 0 & T3 & NO \\
\hline 22 & & 72 & ultrasound & $\mathrm{T} 2$ & isthmus & no & 21 & yes & bilateral & 2 & yes & 2 & 0 & 5 & 0 & T3 & NO \\
\hline
\end{tabular}

F, female; M, male; LN, lymph node; SC, sentinel compartment; SLN, sentinel lymph node; NSLN, non-sentinel lymph node. 
and reduce expenses in real settings as an alternative procedure to implement a SLNB programme in PTC surgery for institutions without nuclear medicine facilities.

In conclusion, we have demonstrated a satisfactory performance of mSLNB in PTC with clinically negative nodes in the central compartment. mSLNB improves PTC patient staging, which can help physicians to tailor RAI treatment and follow-up. Additionally, mSLNB helps to optimize the benefits of the CCD procedure in PTC patients, thereby not only preventing subsequent surgical procedures due to recurrence in the central compartment in T1/T2 patients but also reducing CCD morbidity in $\mathrm{T} 3$ with minimal extrathyroidal extension with pathological-negative nodes. Nonetheless, further prospective studies are needed to validate the clinical value of mSLNB.

\section{Conflict of interest}

The authors declare no conflict of interests.

\section{Source of funding}

No specific funding or grant was received for this study. Sysmex España S.L. provided the materials and reagents required.

\section{Acknowledgements}

We would like to thank the personnel of the Surgical Unit and Pathology Laboratory for their work and contribution to the study. We also would like to thank Sysmex España for their technical support.

\section{References}

[1] Clayman GL, Eisele DW, Ridge J a. Consensus statement on central neck dissection terminology and classification for thyroid cancer. Arch Otolaryngol Head Neck Surg 2010;136:224. https://doi.org/10.1001/archoto.2009.523.

2] Haugen BR, Alexander EK, Bible KC, Doherty G, Mandel SJ, Nikiforov YE, et al. American thyroid association management guidelines for adult patients with thyroid nodules and differentiated thyroid cancer. Thyroid 2015. https:// doi.org/10.1089/thy.2015.0020. 2015;26:thy.2015.0020.

[3] Mazzaferri EL, Doherty GM, Steward DL. The pros and cons of prophylactic central compartment lymph node dissection for papillary thyroid carcinoma. Thyroid 2009;19:683-9. https://doi.org/10.1089/thy.2009.1578.

[4] Roh J, Park J, Park C Il. Total thyroidectomy plus neck dissection in differentiated papillary thyroid carcinoma patients. Ann Surg 2007;245:604-10. https://doi.org/10.1097/01.sla.0000250451.59685.67.

[5] Giordano D, Valcavi R, Thompson GB, Pedroni C, Renna L, Gradoni P, et al. Complications of central neck dissection in patients with papillary thyroid carcinoma: results of a study on 1087 patients and review of the literature. Thyroid 2012;22:911-7. https://doi.org/10.1089/thy.2012.0011.

[6] NCCN. Thyroid carcinoma. Natl Compr Cancer Netw 2015. https://doi.org/ 10.1136/bmj.2.5247.313-a.

[7] Pereira JA, Jimeno J, Miquel J, Iglesias M, Munné A, Sancho JJ, et al. Nodal yield, morbidity, and recurrence after central neck dissection for papillary thyroid carcinoma. Surgery 2005;138:1095-100. https://doi.org/10.1016/ j.surg.2005.09.013. discussion 1100-1.

[8] Zaydfudim V, Feurer ID, Griffin MR, Phay JE. The impact of lymph node involvement on survival in patients with papillary and follicular thyroid carcinoma. Surgery 2008;144:1070-8. https://doi.org/10.1016/j.surg.2008.08. 034.

[9] Chadwick D, Kinsman R, Walton P. The British association of endocrine \& thyroid surgeons fifth national audit report. Br Assoc Endocr Thyroid Surg 2017:196.

[10] Le ARTIC, Lamartina L, Borget I, Mirghani H, Ghuzlan A Al, Berdelou A, et al. Surgery for neck recurrence of differentiated thyroid cancer: outcomes and risk factors. J Clin Endocrinol Metab 2017;102:1020-31. https://doi.org/ $10.1210 /$ jc.2016-3284

[11] Chéreau N, Buffet C, Trésallet C, Tissier F, Leenhardt L, Menegaux F. Recurrence of papillary thyroid carcinoma with lateral cervical node metastases: predictive factors and operative management. Surgeon (United States) 2016;159: 755-62. https://doi.org/10.1016/j.surg.2015.08.033.

[12] B.H.-H L, T.W.H S, A.O.-K C, C.-Y L, K.Y W. Significance of size of persistent/ recurrent central nodal disease on surgical morbidity and response to therapy in reoperative neck dissection for papillary thyroid carcinoma. Thyroid 2017;27:67-73. https://doi.org/10.1089/thy.2016.0337.
[13] Mark L. Urken, MD 1, Mira Milas, MD 2, Gregory W. Randolph, MD 3, Ralph Tufano, MD 4, Donald Bergman, MD 5, Victor Bernet, MD 6, et al. Management of recurrent and persistent metastatic lymph nodes in well-differentiated thyroid cancer: a multifactorial decision-making guide for the Thyroid Cancer Care Collaborative. Head Neck 2014;36:1391. https://doi.org/10.1002/ HED.

[14] Pasieka J. Sentinel lymph node biopsy in the management of thyroid disease. Br J Surg 2001;88:321-2. 2001.

[15] Rubello D, Pelizzo MR, Al-Nahhas A, Salvatori M, O'Doherty MJ, Giuliano AE, et al. The role of sentinel lymph node biopsy in patients with differentiated thyroid carcinoma. Eur J Surg Oncol 2009;32:917-21. https://doi.org/ 10.1016/j.ejso.2006.03.018.

[16] Pelizzo MR, Toniato A, Sorgato N, Losi A, Torresan F, Merante Boschin I. 99TC nanocolloid sentinel node procedure in papillary thyroid carcinoma: our mono-institutional experience on a large series of patients. Acta Otorhinolaryngol Ital 2009;29:321-5.

[17] Rubello D, C N, I MB, A T, A P, L R, et al. Sentinel lymph node (SLN) procedure with patent $\mathrm{V}$ blue dye in 153 patients with papillary thyroid carcinoma (PTC): is it an accurate staging method? J Exp Clin Cancer Res 2006;25:483-6.

[18] Ji YB, Lee KJ, Park YS, Hong SM, Paik SS. Clinical efficacy of sentinel lymph node biopsy using methylene blue dye in clinically node-negative papillary thyroid carcinoma. Ann Surg Oncol 2012:1868-73. https://doi.org/10.1245/ s10434-011-2109-1.

[19] White ML, Gauger PG, Doherty GM. Central lymph node dissection in differentiated thyroid cancer. World J Surg 2007;31:895-904. https://doi.org/ 10.1007/s00268-006-0907-6.

[20] Anand S. The role of sentinel lymph node biopsy in patients with differentiated thyroid carcinoma. Eur J Surg Oncol 2009;32:917-21.

[21] Cunningham DK, Yao K a, Turner RR, Singer FR, Van Herle AR, Giuliano AE. Sentinel lymph node biopsy for papillary thyroid cancer: 12 years of experience at a single institution. Ann Surg Oncol 2010;17:2970-5. https://doi.org| 10.1245/s10434-010-1141-X.

[22] Garcia-Burillo A, Roca Bielsa I, Gonzalez O, Zafon C, Sabate M, Castellvi J, et al SPECT/CT sentinel lymph node identification in papillary thyroid cancer: lymphatic staging and surgical management improvement. Eur J Nucl Med Mol Imaging 2013;40:1645-55. https://doi.org/10.1007/s00259-013-2476-x.

[23] Assadi M, Yarani M, Zakavi SR, Jangjoo A, Memar B, Treglia G, et al. SLN mapping in PTC using combined radiotracer and blue dye methods. Endokrynol Pol 2014;65:281-6. https://doi.org/10.5603/EP.2014.0038.

[24] Balasubramanian SP, Harrison BJ. Systematic review and meta-analysis of sentinel node biopsy in thyroid cancer. Br J Surg 2011;98:334-44. https:/ doi.org/10.1002/bjs.7425.

[25] Ramin S, Azar FP, Malihe H. Methylene blue as the safest blue dye for sentinel node mapping: emphasis on anaphylaxis reaction. Acta Oncol 2011;50: 729-31. https://doi.org/10.3109/0284186X.2011.562918.

[26] Trigo JM, Capdevila J, Grande E, Grau J, Lianes P. Thyroid cancer: SEOM clinical guidelines. Clin Transl Oncol 2014;16:1035-42. https://doi.org/10.1007/ s12094-014-1224-4.

[27] Portinari M, Carcoforo P. Radioguided sentinel lymph node biopsy in patients with papillary thyroid carcinoma. Gland Surg 2016;5:591-602. https:// doi.org/10.21037/gs.2016.11.08.

[28] Weissleder R, Elizondo G, Wittenberg J, Lee AS, Josephson L, Brady TJ. Ultrasmall superparamagnetic iron oxide: an intravenous contrast agent for assessing lymph nodes with MR imaging. Radiology 1990;175:494-8. https:// doi.org/10.1148/radiology.175.2.2326475.

[29] Thill M, Kurylcio A, Welter R, van Haasteren V, Grosse B, Berclaz G, et al. The Central-European SentiMag study: sentinel lymph node biopsy with superparamagnetic iron oxide (SPIO) vs. radioisotope. Breast 2014;23:175-9. https://doi.org/10.1016/j.breast.2014.01.004.

[30] Rubio IT, Diaz-Botero S, Esgueva A, Rodriguez R, Cortadellas T, Cordoba O et al. The superparamagnetic iron oxide is equivalent to the Tc99 radiotracer method for identifying the sentinel lymph node in breast cancer. Eur J Surg Oncol 2015;41:46-51. https://doi.org/10.1016/j.ejso.2014.11.006.

[31] Piñero-Madrona a, Torró-Richart J a, de León-Carrillo JM, de Castro-Parga G Navarro-Cecilia J, Domínguez-Cunchillos F, et al. Superparamagnetic iron oxide as a tracer for sentinel node biopsy in breast cancer: a comparative noninferiority study. Eur J Surg Oncol 2015. https://doi.org/10.1016/j.ejso.2015. 04.017.

[32] Ghilli M, Carretta E, Di Filippo F, Battaglia C, Fustaino L, Galanou I, et al. The superparamagnetic iron oxide tracer: a valid alternative in sentinel node biopsy for breast cancer treatment. Eur J Cancer Care (Engl) 2017;26. https:// doi.org/10.1111/ecc.12385. n/a-n/a. doi.

[33] Douek M, Klaase J, Monypenny I, Kothari A, Zechmeister K, Brown D, et al. Sentinel node biopsy using a magnetic tracer versus standard technique: the SentiMAG multicentre trial. Ann Surg Oncol 2014:1237-45. https://doi.org 10.1245/s10434-013-3379-6.

[34] Karakatsanis A, Christiansen PM, Fischer L, Hedin C, Pistioli L, Sund M, et al. The Nordic SentiMag trial: a comparison of super paramagnetic iron oxide (SPIO) nanoparticles versus Tc99and patent blue in the detection of sentinel node (SN) in patients with breast cancer and a meta-analysis of earlier studies. Breast Canc Res Treat 2016;157:281-94. https://doi.org/10.1007/s10549-0163809-9.

[35] Edge SB, Compton CC. The american joint committee on cancer: the 7th edition of the AJCC cancer staging manual and the future of TNM. Ann Surg Oncol 2010;17:1471-4. https://doi.org/10.1245/s10434-010-0985-4. 
[36] Carcoforo P, Portinari M, Feggi L, Panareo S, De Troia A, Zatelli MC, et al. Radioguided selective compartment neck dissection improves staging in papillary thyroid carcinoma: a prospective study on 345 patients with a 3-year followup. Surgery 2014;156:147-57. https://doi.org/10.1016/j.surg.2014.03.045.

[37] Pacini F, Castagna MG, Brilli L, Pentheroudakis G. Thyroid cancer: ESMO clinical practice guidelines for diagnosis, treatment and follow-up. Ann Oncol 2012;23. https://doi.org/10.1093/annonc/mds230.

[38] Huxley N, Jones-Hughes T, Coelho H, Snowsill T, Cooper C, Meng Y, et al A systematic review and economic evaluation of intraoperative tests [RD-100 one-step nucleic acid amplification (OSNA) system and metasin test] for detecting sentinel lymph node metastases in breast cancer. Health Technol Assess (Rockv) 2015;19:1-246. https://doi.org/10.3310/hta19020.

[39] Perros P, Colley S, Boelaert K, Evans C, Evans RM, Gerrard GE, et al. British thyroid association guidelines for the management of thyroid cancer. Br Med J 2014;81:901. https://doi.org/10.1016/B978-1-4377-0324-5.00002-X.

[40] Rubello D, Colletti PM, Cook GJ. What is the role of radionuclide sentinel lymph node biopsy and dissection in papillary thyroid cancer? Nucl Med Commun 2015;36:1. https://doi.org/10.1097/MNM.0000000000000327.

[41] Yan X, Zeng R, Ma Z, Chen C, Chen E, Zhang X, et al. The utility of sentinel lymph node biopsy in papillary thyroid carcinoma with occult lymph nodes. PLoS One 2015;10:e0129304. https://doi.org/10.1371/journal.pone.0129304.

[42] Hao RT, Chen J, Zhao LH, Liu C, Wang OC, Huang GL, et al. Sentinel lymph node biopsy using carbon nanoparticles for Chinese patients with papillary thyroid microcarcinoma. Eur J Surg Oncol 2017;38:718-24. https://doi.org/10.1016/ j.ejso.2012.02.001.

[43] Gao W, Zhao T, Liang J, Lin Y. Is the ratio superior to the number of metastatic lymph nodes in addressing the response in patients with papillary thyroid cancer? Medicine (Baltim) 2018;97. https://doi.org/10.1097/MD.00000000 00009664. e9664.

[44] Jong-Lyel R, Woo PJ, Junhyeop J, Gyungyup G, Kyung-Ja C, Seung-Ho C, et al.
Extranodal extension of lymph node metastasis as a prognostic indicator of recurrence and survival in papillary thyroid carcinoma. J Surg Oncol 2017;116:450-8. https://doi.org/10.1002/jso.24713.

[45] Zhang T, Qu N, Hu J, Shi R, Wen D, Sun G, et al. Mediastinal lymph node metastases in thyroid Cancer: characteristics, predictive factors, and prognosis. 2017. https://doi.org/10.1155/2017/1868165. 2017.

[46] Lee YJ, Kim DW, Shin GW, Heo YJ, Baek JW, Cho YJ, et al. Appropriate frequency and interval of neck ultrasonography surveillance during the first 10 years after total thyroidectomy in patients with papillary thyroid carcinoma. Front Endocrinol (Lausanne) 2018;9:1-5. https://doi.org/10.3389/fendo.2018. 00079.

[47] Machens A, Holzhausen HJ, Dralle H. Skip metastases in thyroid cancer leaping the central lymph node compartment. Arch Surg 2004;139:43-5. https:// doi.org/10.1001/archsurg.139.1.43.

[48] Peg V, Espinosa-Bravo M, Vieites B, Vilardell F, Antúnez JR, De Salas MS, et al. Intraoperative molecular analysis of total tumor load in sentinel lymph node: a new predictor of axillary status in early breast cancer patients. Breast Canc Res Treat 2013;139:87-93. https://doi.org/10.1007/s10549-013-2524-z.

[49] Del Carmen S, Gatius S, Franch-Arcas G, Baena JA, Gonzalez O, Zafon C, et al. Concordance study between one-step nucleic acid amplification and morphologic techniques to detect lymph node metastasis in papillary carcinoma of the thyroid. Hum Pathol 2016;48:132-41. https://doi.org/10.1016/ j.humpath.2015.09.020.

[50] Kaczka K. First OSNA in PTC comparison of hsitopathology and qPCR Endokrynol Pol 2014;64:480-93. https://doi.org/10.5603/EP.

[51] Balasubramanian SP, Brignall J, Lin HY, Stephenson TJ, Wadsley J, Harrison BJ, et al. Sentinel node biopsy in papillary thyroid cancer-what is the potential? Langenbeck's Arch Surg 2014;399:245-51. https://doi.org/10.1007/s00423014-1168-8. 